\title{
Retroperitoneal hematoma: Vascular complication after percutaneous coronary intervention
}

\author{
Matthias Heuer, Gernot Maximilian Kaiser, \\ Christoph Moenninghoff, Andreas Paul
}

\section{CASE REPORT}

An 81-year old female underwent percutaneous coronary intervention (PCI) because of atrial fibrillation on current anticoagulation with $100 \mathrm{mg}$ aspirin/d. 48-hours following the procedure, the patient became hypotensive. Signs of hematoma at the puncture site in the right groin were recoded on general physical examination. The abdomen was distended with tenderness in the right iliac fossa. Additionally the patient suffered from stabbing pain in the right lower abdomen. The hemoglobin level fell from 13 to $8 \mathrm{~g} / \mathrm{dl}$.

An abdominal CT scan performed with administration of intravenous contrast media revealed a large, biphasic right retroperitoneal hematoma (zone II) with a craniocaudal dimension of $22 \mathrm{~cm}$ (Figure 1). An active bleeding from the right external iliac artery was demonstrated by an ascending contrast extravasation (arrow) between the hematoma layers (serum/corpuscular part).

The patient was managed by exploratory laparotomy. Intraoperative findings were significant for a retroperitoneal hematoma (RPH) with an injured right external iliac artery due to puncture wound and diffuse

Matthias Heuer ${ }^{1}$, Gernot Maximilian Kaiser ${ }^{1}$, Christoph Moenninghoff ${ }^{2}$, Andreas Paul ${ }^{1}$

Affiliations: ${ }^{1}$ Department of General, Visceral and Transplantation Surgery, University Hospital Essen, Germany; ${ }^{2}$ Department of Diagnostic and Interventional Radiology and Neuroradiology, University Hospital Essen, Germany.

Corresponding Author: Matthias Heuer, Department of General-, Visceral- and Transplantation Surgery, University Hospital Essen, Hufelandstr, 55, 45122 Essen, Germany. Phone: +49-201-723-84010; Fax: +49-201723-1137; E-mail: matthias.heuer@uk-essen.de

Received: 06 September 2010

Accepted: 19 October 2010

Published: 15 November 2010 bleeding. These could be surgically controlled by running suture reconstruction of the artery lesion and subtly, retroperitoneal hemostasis.

\section{DISCUSSION}

The incidence of RPH occurs in approximately $1 \%$ of patients who sustain PCI. Features of RPH include hypotension (92\%), diaphoresis (58\%), groin pain (46\%), abdominal pain (42\%) and back pain (23\%). From the clinical point of view, the vast majority of $\mathrm{RPH}$ can be managed nonoperatively. Indication for operative management of RPH includes hemodynamic instability related to the injury [1].

\section{CONCLUSION}

$\mathrm{RPH}$ with PCI is rare. Laparotomy may be required in unstable patient with RPH after PCI.

$$
* * * * * * * * *
$$

Heuer M, Kaiser GM, Moenninghoff C, Paul A. Retroperitoneal hematoma: Vascular complication after percutaneous coronary intervention. International Journal of Case Reports and Images 2010;1(3): 15-16.

$$
* * * * * * * * * \text {. }
$$

doi:10.5348/ijcri-2010-11-7-CI-4

\section{Author Contributions}

Matthias Heuer - Conception and design, Acquisition of data, Analysis and interpretation of data, Drafting the article, Critical revision of the article, Final approval of the version to be published 
Gernot Maximilian Kaiser - Conception and design, Acquisition of data, Analysis and interpretation of data, Drafting the article, Critical revision of the article, Final approval of the version to be published Christoph Moenninghoff - Conception and design, Acquisition of data, Analysis and interpretation of data, Drafting the article, Critical revision of the article, Final approval of the version to be published Andreas Paul - Conception and design, Acquisition of data, Analysis and interpretation of data, Drafting the article, Critical revision of the article, Final approval of the version to be published

\section{Guarantor}

The corresponding author is the guarantor of submission.

\section{Conflict of Interest}

Authors declare no conflict of interest.

\section{Copyright}

(C) Matthias Heuer et. al. 2010; This article is distributed under the terms of Creative Commons attribution 3.0 License which permits unrestricted use, distribution and reproduction in any means provided the original authors and original publisher are properly credited. (Please see www.ijcasereportsandimages.com/copyrightpolicy.php for more information.)

\section{REFERENCES}

1. Farouque HM, Tremmel JA, Raissi Shabari F, Aggarwal M, Fearon WF, Ng MK, et al. Risk factors for the development of retroperitoneal hematoma after percutaneous coronary intervention in the era of glycoprotein IIb/IIIa inhibitors and vascular closure devices. J Am Coll Cardiol 2005;45:363-8.

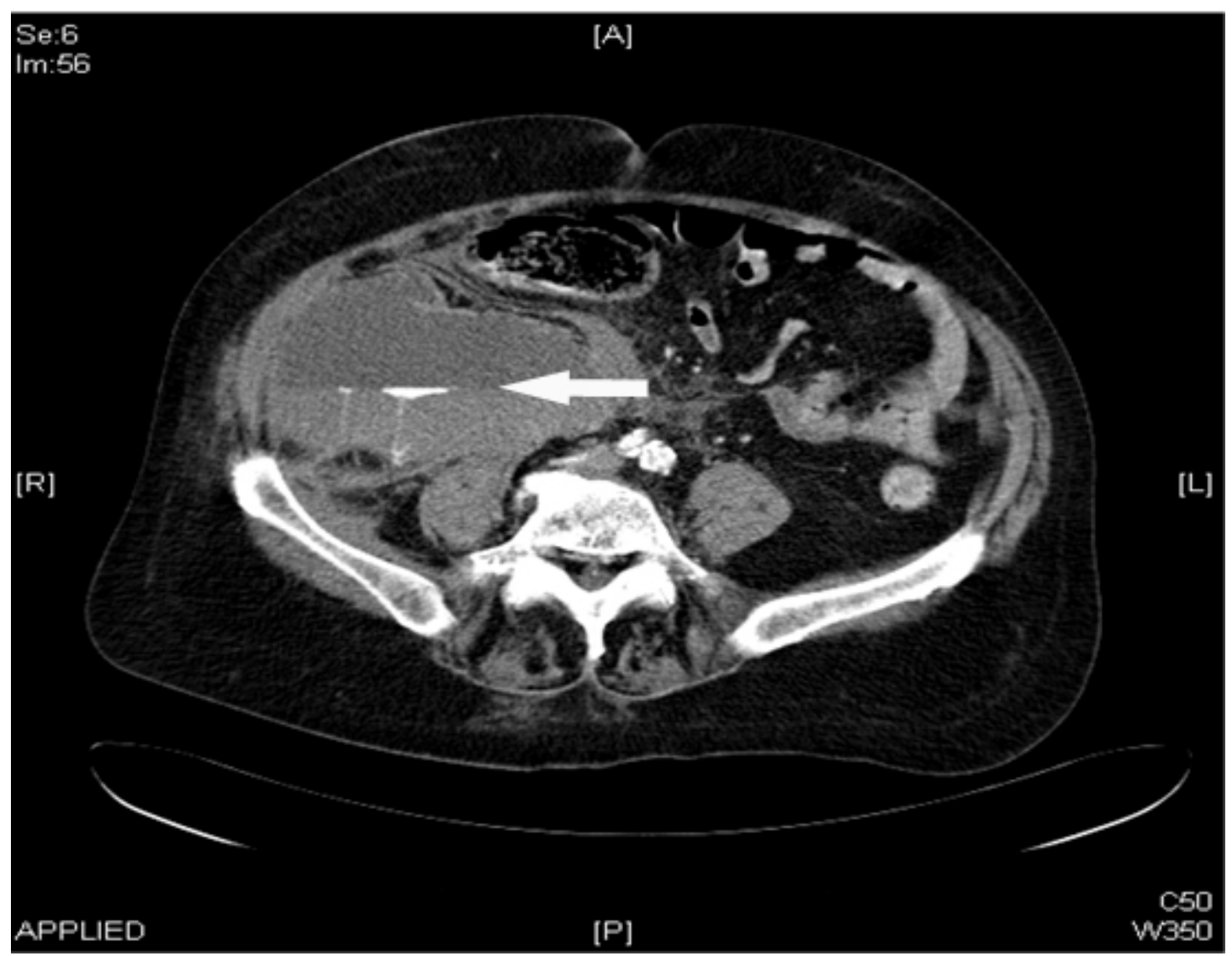

Figure 1: Abdominal CT scan performed with administration of intravenous contrast media revealed a large, biphasic retroperitoneal hematoma (arrow). 